\title{
Localized Cutaneous Mastocytosis following Radioiodine Ablation Therapy: A Case Report and Review of Literature \\ Michael W Wangia ${ }^{1 *}$, Kelly D. Tepedino², Francisco A Ramos-Caro, Jacqueline J Russo² and Frederick L. Glavin ${ }^{2}$
}

${ }^{1}$ Department of Dermatology, University of Florida College of Medicine, Florida, USA

${ }^{2}$ Medical Student MS-IV, University of Florida College of Medicine, Florida, USA

\section{Introduction}

Cutaneous mastocytosis (CM) is characterized by the aberrant proliferation and accumulation of mast cells in the skin without any evidence of extra-cutaneous organ involvement [1]. There is no clear pathologic mechanism that has been presented to explain the development of cutaneous mastocytosis. We present a case of CM following adjuvant radioiodine ablation therapy for papillary thyroid carcinoma. There are few case reports of cutaneous mastocytosis arising within a localized area of external beam radiation therapy. To our knowledge there are no previously reported cases of CM associated with systemic radiotherapy.

\section{Report of a Case}

An 81 year-old woman presented with a red, pruritic rash on the neck and upper chest area that had been slowly progressive over a twelve month period and was refractory to topical therapies such as emollients and antibiotic ointments. Review of systems was positive for hypothyroid symptoms; cold intolerance, weight gain, and fatigue. She had undergone thyroidectomy and adjuvant radioactive iodine therapy one year prior to presentation for treatment of invasive papillary thyroid cancer. Physical examination revealed a large well demarcated erythematous plaque with few areas of scaling on the anterior neck and upper chest (Figure 1). There was a prominent firm mass on her right neck. No adenopathy was noted. Darier's sign was negative, but dermatographia was evident. $\mathrm{KOH}$ (potassium hydroxide) preparation was negative for dermatophytosis or candidiasis. Our differential diagnosis included an irritant or allergic contact dermatitis, radiationinduced dermatitis, histiocytosis, and mycosis fungoides. A punch biopsy of lesional skin revealed increased numbers of mast cells throughout the dermis without evidence of spongiosis, and stained positively with mast cell tryptase (MCT), and Giemsa stains (Figures 2 and 3).The patient denied any systemic symptoms such as flushing, hypotension, tachycardia, anaphylaxis, dizziness, headaches, abdominal pain, and diarrhea. She had no symptoms suggesting osteoarticular involvement. Complete blood count with differential, liver function tests, and serum tryptase levels were all within normal limits. We referred the patient to surgical oncology for further evaluation of the

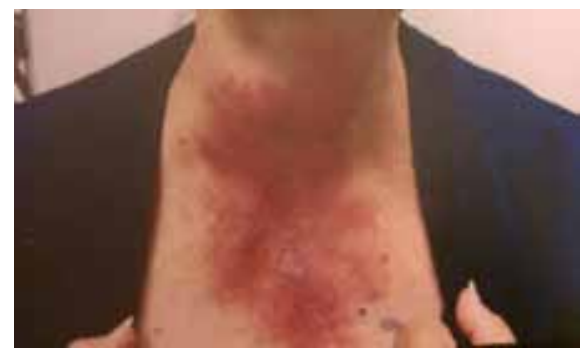

Figure 1: Well-demarcated erythematous plaque with few areas of scaling on the anterior neck and upper chest.

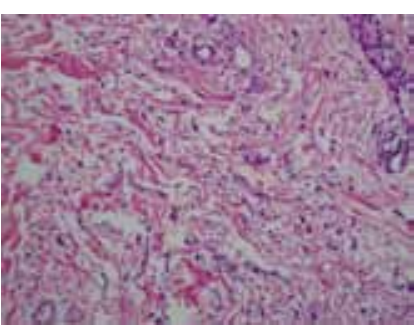

Figure 2: Cutaneous Mastocytosis. Skin with superficial ectatic vessels and an increased number of infiltrating mast cells (40x, Hematoxylin and Eosin Stain).

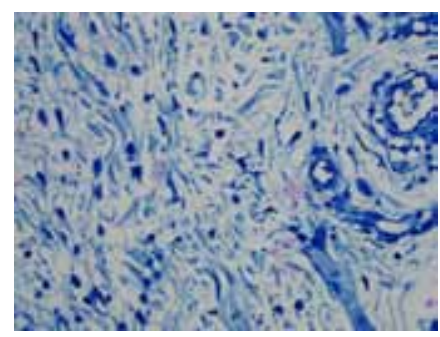

Figure 3: Mast cell infiltration highlighted by Geimsa Stain (400x).

right neck mass for possible recurrent papillary thyroid cancer. Marked improvement of the rash was observed within 4 weeks with use of triamcinolone ointment and cetirizine.

\section{Discussion}

Cutaneous mastocytosis $(\mathrm{CM})$ is characterized by a primary pathologic increase in mast cells limited to the skin without any evidence of extra-cutaneous organ involvement [1]. Urticaria pigmentosa, solitary mastocytoma, telangiectasia macularis eruptiva perstans (TMEP), and diffuse cutaneous mastocytosis are four notable subtypes. The majority of childhood cases of CM result in spontaneous remission. Adults usually have chronic disease, rarely transforming into an aggressive type associated with myelodysplasia,

*Corresponding author: Michael W. Wangia, MD, Department of Dermatology, University of Florida College of Medicine, Gainesville, FL 32610, USA, Tel: 352.392.4984; Fax: 352.392.5376; E-mail: wangim@dermatology.med.ufl.edu

Received May 31, 2012; Accepted June 18, 2012; Published June 22, 2012

Citation: Wangia MW, Tepedino KD, Ramos-Caro FA, Russo JJ, Glavin FL (2012) Localized Cutaneous Mastocytosis following Radioiodine Ablation Therapy: A Case Report and Review of Literature. J Nucl Med Radiat Ther 3:133. doi:10.4172/21559619.1000133

Copyright: (c) 2012 Wangia MW, et al. This is an open-access article distributed under the terms of the Creative Commons Attribution License, which permits unrestricted use, distribution, and reproduction in any medium, provided the original author and source are credited. 
myeloproliferative disorders, or leukemia [1,2]. The skin and bone marrow are the most frequently affected organs, but occasionally the spleen, lymph nodes, and liver are also affected. The development of systemic mastocytosis(SM) has been associated with activating somatic mutations in the $c$-kit protooncogene and its ligand stem cell factor (SCF). However, there are no clear pathologic mechanism that has been presented that explain the development of CM [2].

We present a rare case of localized cutaneous mastocytosis following systemic adjuvant radioactive iodine therapy for treatment of invasive papillary thyroid carcinoma. The striking feature about this case is the presentation of $\mathrm{CM}$ as a localized, well demarcated erythematous plaque mimicking a contact or radiation-induced dermatitis. High affinity of thyroid tissue for radioactive iodine may explain concentration of radioisotope $\left({ }^{131} \mathrm{I}\right)$ in anterior neck region and resultant localized dermatitis. There are three other reported cases describing radiationinduced localized $\mathrm{CM}$ following external beam radiation for the treatment of breast cancer $[3,4,5]$. Comte $\mathrm{C}$ et al. describe a case of urticaria pigmentosa localized to the irradiation field in a woman who was treated with radiotherapy for breast cancer. Soilleux EJ et al. report a case of a 62 year old woman who had undergone conservative surgery and localized radiotherapy for right breast cancer and developed localized cutaneous mastocytosis two years after therapy. In 1971, a case of localized cutaneous mastocytosis was reported in a 61 year old woman, 4 months after the completion of adjuvant radiation therapy for treatment of breast cancer. In this case, this rash developed after resolution of expected primary irradiation reaction [5]. Finally, Eagan JW et al. describes a case of systemic mastocytosis after long-term treatment of polycythemia vera with radioactive phosphorus [6].

The association between radiotherapy and mast cell infiltration is not clearly understood. However, cutaneous fibrosis is well-known sequelae of ionizing radiation-induced tissue injury. It has been proposed that radiation induces mast cell degranulation and tryptase secretion, which may contribute to skin fibrosis [7]. Comte $\mathrm{C}$ et al. have suggested koebnerization phenomenon as a pathomechanism for radiation-induced CM. This is evidenced by mast cell infiltration limited to only irradiated fields. In our case, concentration of ${ }^{131} \mathrm{I}$ in the thyroid gland simulates a focal area of irradiation akin to that seen in external beam radiation therapy. Interestingly, radiation therapy has been utilized in the treatment of severe intractable bone pain in patients with advanced systemic mast cell disease [8]. Poirier et al. have used radiotherapy in treatment of incompletely excised canine mast cell tumors, suggesting variability in the effects of ionizing radiation to mast cells [9].

The role of an underlying neoplastic process (possibly recurring papillary thyroid cancer) in developing CM cannot be determined. However, adult CM has been associated most commonly with malignancies of hematopoietic origin.

Given the absence of clinically relevant signs suggestive of systemic mastocytosis and normal blood counts and serum tryptase levels, further diagnostic work-up was deferred.

\section{References}

1. Amon U, Hartmann K, Horny HP, Nowak A (2010) Mastocytosis - an update. J Dtsch Dermatol Ges 8: 695-712.

2. Hartmann K, Henz BM (2001) Mastocytosis: recent advances in defining the disease. Br J Dermatol 144: 682-695.

3. Comte C, Bessis D, Dereure O, Guillot B (2003) Urticaria pigmentosa localized on radiation field. Eur J Dermatol 13: 408-409.

4. Soilleux EJ, Brown VL, Bowling J (2009) Cutaneous mastocytosis localized to a radiotherapy field. Clin Exp Dermatol 34: 111-112.

5. Macdonald A, Feiwel M (1971) Cutaneous mastocytosis: an unusual radiation dermatitis. Proc R soc Med 64: 29-30.

6. Eagan JW Jr, Baughman KL, Miller S, Conley CL, Eggleston JC (1977) Systemic mastocytosis in a patient with polycythemia vera treated with radioactive phosphorus. Blood 49: 563-571.

7. Albrecht M, Müller K, Köhn FM, Meineke V, Mayerhofer (2007) lonizing radiation induces degranulation of human mast cells and release of tryptase. Int J Radiat Biol 83: 535-541.

8. Hesselmann S, Micke O, Schaefer U, Willich N (2002) Systemic mast cell disease (SMCD) and bone pain. A case treated with radiotherapy. Strahlenther Onkol 178: 275-279.

9. Poirier VJ, Adams WM, Forrest LJ, Green EM, Dubielzig RR, et al. (2006) Radiation therapy for incompletely excised grade II canine mast cell tumors. J Am Animal Hosp Assoc 42: 430-434. 